\title{
Evaluation of land use-transportation systems with the Analytic Network Process
}

\author{
Reza Banai \\ University of Memphis ${ }^{\text {a }}$
}

\begin{abstract}
Developments in models and methods of urban systems have increasingly drawn attention to the joint effect of land use and transportation on behavioral and policy relevance, with multicriteria evaluation of and attention to the site-level analysis of spatial impacts. In this paper, we use Saaty's Analytic Network Process (ANP), a systems-oriented method, to contribute to the emerging methodological developments in land use and transportation systems evaluation, planning, and forecasting. The ANP is applied to the problem of light rail route selection with station area land use and property value among multiple criteria. The application shows how the analysis of land use and transportation as elements of an urban system with feedback is facilitated by the ANP with data parsimony in the ex ante estimation of site-specific, spatial-economic impacts.
\end{abstract}

Keywords: Land Use, Transportation, Urban Systems, Light Rail Transit (LRT), Route Selection, Market Impact Share, Land Use and Property Value Impact, Analytic Network Process (ANP), Analytic Hierarchy Process (AHP), GIS

\section{Introduction}

The basic idea that land use and transportation are connected in a "two-way" relationship was initially suggested in the 1950s and 1960s during discussions of urban traffic as a function of land use (Mitchell and Rapkin 1954) and in treatment of the idea in regional science that land use is influenced by transportation (see Hall 1996). The concept of land use and transportation as elements of an interactive, nonlinear system or network with feedback has endured. However, subsequent issues have centered on the methodological concerns of how to better measure the land use/transportation interaction and determine the policy implications.

A wide variety of ex ante and ex post methods are used in planning, forecasting, and evaluation of land use/transportation systems. ${ }^{1}$ The concept of land use and transportation as elements of an urban system with feedback, however, reveals some limitations of commonly used

\footnotetext{
arbanai@memphis.edu

${ }^{1}$ The methods include multicriteria evaluation analysis (ranking methods, multi-objective optimization, multiattribute utility analysis), statistical (regression), survey (interviews, contingent valuation), scenario (trend case study, growth scenario), deterministic (input/output, benefit/cost, cost-effectiveness), quasi-experimental methods, simulation using GIS, and case comparisons. The case comparison, survey method, cost/benefit and multicriteria analysis are examples of the ex ante or "predictive" evaluation of transportation alternatives and of estimation of the land development and redevelopment impact of transportation. Quasi-experimental and hedonic price models are among ex post "evaluative" methods. For a comprehensive discussion of the strength and weaknesses of methods and data requirements for LRT station area analysis of impact, see Transit Cooperative Research Program (1998). 
methods. These limitations are evident in the evaluation of LRT route alternatives with joint consideration of land use and transportation. The evaluation methods are commonly of the linear and ex-post variety that limit application to land use/transportation systems with interaction. These shortcomings apply equally as well to the evaluation methods of the ex ante variety like multicriteria, multi-attribute, and optimization methods. Among the ex ante variety, the case comparison method is economical to administer, but its findings have limited transferability. In the context of rail transit projects, variability requires attention to the conditions specific to place and context in the empirical investigation of the impacts. (For a comprehensive review and discussion of the methods used in transit impact analysis, see Transit Cooperative Research Program 1998 and Cervero and Landis 1993.)

In this paper, Saaty's, Analytic Network Process (ANP) is applied to an archetypal problem of public transit (LRT) route selection with land use interaction. The ANP is a systems-oriented method, which is the general, nonlinear form of the Analytic Hierarchy Process (AHP) - a multi-criteria evaluation, ranking, and decision-making method developed by Saaty (1980) with vast and wide-ranging applications (for a survey of the applications, see Zahedi 1986 and Saaty and Vargas 2001. The ANP surmounts the limitations of simple linear methods of planning, forecasting, and evaluation in situations such as LRT route selection, where land use and transportation system elements-commonly mixed tangibles and intangibles-are known to interact but are considered cumbersome to take into account with standard statistical, analysis, and optimization methods. The ANP provides contributions with: 1) a problem definition (land use/transportation is defined by a network structure of interrelated elements); 2) multi-attribute qualitative and quantitative evaluation of land use and transportation; 3 ) high resolution, site-specific, small area spatial analysis; and 4) prediction with limited data. In brief, ANP facilitates the evaluation of the LRT route alignment alternatives with diverse spatial, economic, political, and environmental factors that influence land use/transportation interaction with a small number of station area neighborhoods characterizing the impact areas. Furthermore, ANP provides a wide-ranging, inclusive analytic framework in which land use/transportation as elements of a system with feedback is specified deductively, and in which multiple evaluation criteria and their influence are determined in a site-specific context inductively. The structural framework and probability-like measure of the multiple criteria facilitate the interpretation of findings akin to path analysis techniques of statistics, and ratio-methods like benefit/cost analysis.

Given the pedagogic purpose of the paper, a step-by-step introduction of both methods-ANP and AHP_-is given comparatively. The introduction is aimed at readers who are likely familiar with AHP, since it was introduced in the early 1970s, but who are likely less familiar with its general form, ANP, that has only recently received attention through applications in literature. The ANP is introduced with two simplified examples before the case application to an LRT route alternative selection problem. It was found that ANP methodological contributions are aligned with developments in urban systems analytical methods, and these are briefly reviewed. The paper begins with a brief description of the background and rationale for a case application of ANP in LRT route selection. 


\section{Land use-transportation: An urban system with feedback}

\subsection{Problem context}

Two route alignment alternatives, proposed for light rail transit currently under consideration in the city of Memphis, Tennessee, in the United States, provide context for a case application (figure 1).
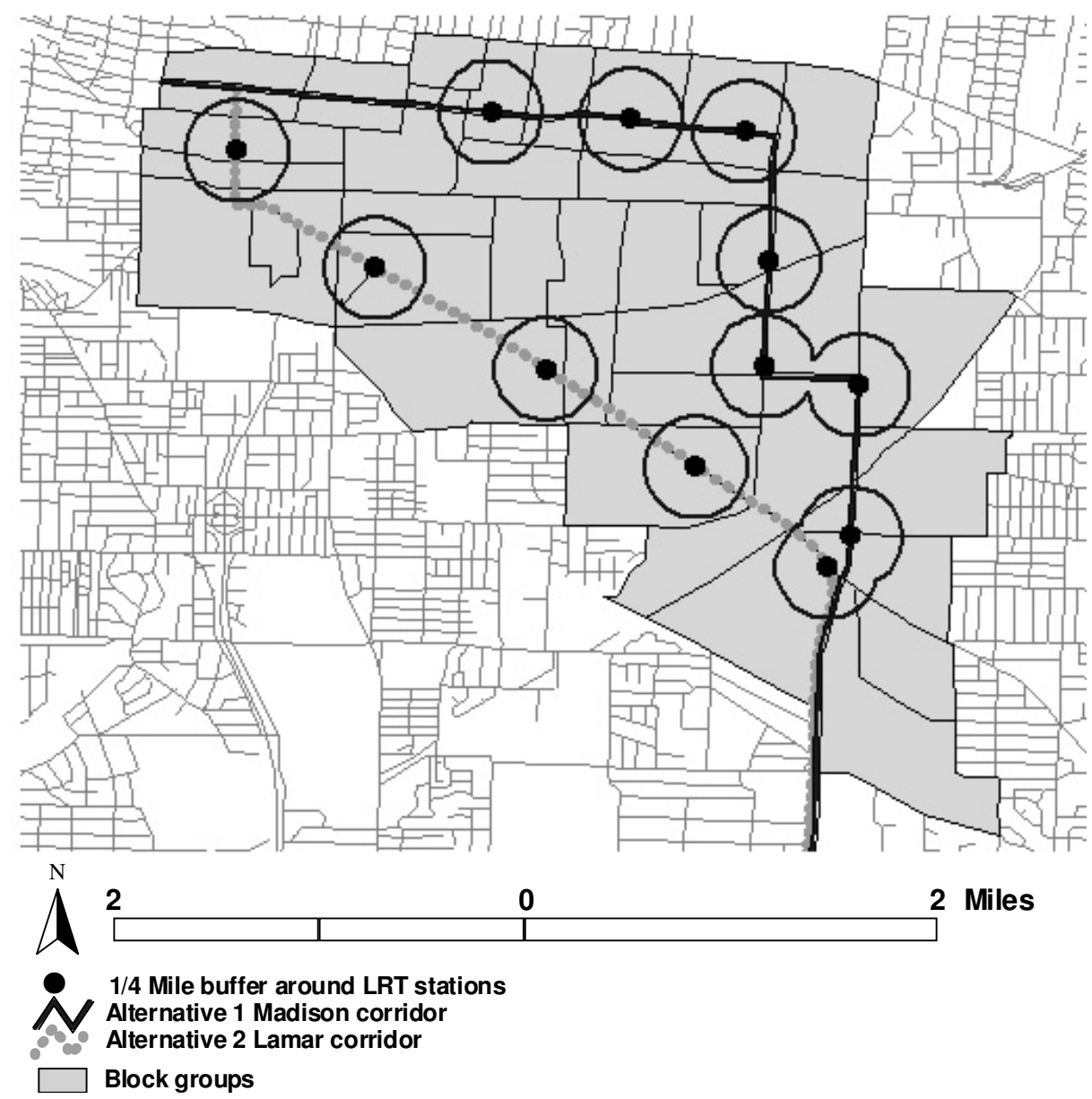

Figure 1: Block groups containing or adjoining quarter-mile LRT station areas along two route alignment alternatives.

The route alternatives were assessed in a recent study that used AHP with multiple land use and transportation criteria to determine the best corridor and route alignment (Banai 2006; Memphis Area Transit Authority 1997). That study considered the public transit planning process in Memphis, which identified corridors and determined alignment alternatives within the best corridor (Memphis Area Transit Authority 2001). The Federal Transit Administration New Starts planning process determined the multiple land use and public transit criteria; the AHP model reflected public transportation decision-making in deference to federal New Starts guidelines as well as local priorities and preferences. The alternative corridors and routes 
were assessed quantitatively in deference to the multiple criteria in a unified framework. The goal, participant groups, criteria, sub-criteria, and alternatives constituted various elements of a unified framework of public transportation decision-making process with relative influence on the outcome (see Banai 2006).

A logical extension of that study is to determine the land use impacts of the two highest rated LRT route alignment alternatives of neighborhoods within a quarter-mile of the station area. The extension is possible analytically from the linear method of AHP to the nonlinear method of ANP. The findings should indicate whether or not the best alternative will fare equally as well with land use impacts. Since literature generally indicates that land use and transportation have a reciprocal relationship, the ANP method, with a facility to evaluate systems with feedback, is used in this paper.

Given the pedagogic objective of this paper and the focus on method, we have briefly reviewed the place of ANP in the development of urban systems analytical methods and its applications to land use/transportation. It was found that ANP methodological contributions are in alignment with the developments in urban systems analytical methods (Subsection 2.2).

\subsection{Background on method: Urban systems analysis and ANP}

Developments in the analytical models and methods of urban systems increasingly draw attention to the joint effect of land use and transportation on behavioral and policy relevance. Models of the land use/transportation system are developed through case applications and with policy expectations. One example of this genre is LUTRAQ, a model developed to assess the relationships between urban land use, transportation, and air quality. As Calthorpe and Fulton (2001) and others have observed, transportation models developed and applied to the characteristically highway-dependent suburban growth pattern have lacked adequate multi-modal consideration. Transportation planning and forecasting methods particularly lack transit, bike, and walk trips, as well as responsiveness to land use. Emerging metropolitan planning and evaluation methods such as LUTRAQ fill a void in the standard modeling technology used to describe the land use/transportation interaction, and respond to public policy that promotes their joint consideration. Prominent examples of public policy that call for attention to the interrelationship of land use and transportation are two federal legislations in the United States: the Intermodal Surface Transportation Efficiency Act (ISTEA) and the Transportation Equity Act for the Twenty-First Century (TEA 21). Public policy thus provides a new direction in the assessment of transportation alternatives, such as transit route alignment alternatives-if approached jointly, with land use among the multiple functional, economic, and environmental factors.

The joint consideration of land use and transportation has logically progressed to the use of multicriteria evaluation methods and an attention to site-level analysis of spatial impacts. Measurement of the tradeoffs among the criteria is revealed in multi-objective (rather than single objective) optimization (for examples, see Azis 1990; Piantanakulchai 2005; Rogers and Bruen 2000; Shang et al. 2004). This has lead to the popularity of the decision-support systems that play an increasing role in the recent development of urban systems analytical methods used in conjunction with a geographical information system (GIS). The land use/transportation decision-support system is aided by a desktop computer (with either loose coupling or seamless integration) with GIS (Batty 1992; Harris and Batty 1993). The use of GIS has liberated 
urban systems models from the "tyranny" of zones (Wegener 1998) and facilitated site-level spatial analysis (Landis and Zhang 1998). The AHP-the precursor to ANP —is among these very applications (for examples, see Banai 1993; Jiang and Eastman 2000; Li and Yeh 2000; Malczewski 1999; Wu 1998; Wu and Webster 1998; see also Zahedi 1986 for a survey of the applications; see also Saaty and Vargas 2001). The AHP models of the urban system are aligned with the developmental trajectory of models that have generally involved disaggregate land use/transportation relational data analysis in comparison to earlier aggregate data (Garin 1966; Lowry 1964). In addition, AHP models are structurally akin to discrete choice theory, particularly of the nested logit-type variety, commonly with some specification of the chain or hierarchy of individual or collective choice (e.g. employment, housing, shopping, and travel mode choices). However, a recent innovation that includes land use and transportation with feedback loops (de la Barra 2001) highlights the conceptual elegance of nonlinearity in the urban system, which is better served by ANP than by AHP.

The ability to analyze a complex, multidimensional urban system qualitatively and quantitatively is a contributing factor in the development of hybrid methods that combine AHP with other techniques such as statistical, optimization, cellular automata, and fuzzy evaluation ( $\mathrm{Li}$ and Yeh 2000; Wu 1998; Wu and Webster 1998). However, ANP, as the general form of AHP, provides even greater ability to address the basic concept that land use and transportation are elements of a nonlinear system with feedback, compared to the multi-linear mathematics of AHP without feedback (for a basic exposition of ANP, see Saaty 2003). In land use and transportation systems planning and evaluation, and highway or transit route selection decision-making, AHP/ANP applications highlight the importance of multicriteria analysis with mixed tangible and intangible factors and with limited data (Dantas et al. 2001; Jankowski and Richard 1994; Khasnabis and Chaudhury 1994; Yoon and Hwang 1995). Multiple functional, spatial, economic, and ecologic criteria are used in the evaluation of an "optimum" route. The strength of AHP/ANP, compared to commonly used methods in land use and transportation systems, includes a structural flexibility to account for multiple stakeholders with varying goals and preferences in public transportation systems planning (Levine et al. 1999). Compared to benefit/cost analysis methods, a diverse set of factors, both tangible and intangible, with varying short- and long-term time frames, is considered in an analytical framework that includes opportunity and risk as well as benefit and cost (Saaty 2003; Shang et al. 2004; Tabucanon and Lee 1995). However, the lack of interrelationship among land use and transportations systems criteria and the absences of alternatives in AHP applications is a common limitation noted in the literature, and is an impetus for the ANP approach (Piantanakulchai 2005). Transportation systems evaluation factors are commonly structured by separate ANP "control hierarchies" of benefit, cost, opportunity, and risk, and are synthesized to determine the composite priority of alternatives (Saaty 2003). The optimum solution is identified by the highest-scoring alternative. In common applications of ANP, the land use impacts of transportations systems are rarely modeled explicitly in the determination of the best alternative.

The ANP model of the land use/transportation interaction in case application is aligned with urban systems analytical methods that required transportation alternatives be sensitive to land use and site-specific attributes. For example, the urban physical form quality of the area that surrounds the transit station, as well as pedestrian-friendly access to the station from locations with a fine mix of land use and without arterial separation, are factors considered in addition to the commonly used quantitative indicators of physical form (e.g. density) in the 
measurement of the transit use/land use interaction. However, ANP surmounts a limitation of observational studies like the commonly used hedonic models by determining ex ante the land use and property impacts of transit (see Al-Mosaind et al. 1993). Furthermore, statistical and random utility theory-based methods that draw upon a large sample are of limited use in a transportation route selection problem with a small number of parcels or zones; this is the case in the LRT impact study in this paper (figure 1 on page 87). Efficient sampling techniques require taking a subset of the population rather than counting the entire population. Alternatives to the sampling methods, however, are needed to overcome the limitation of statistical sampling methods in situations where the sample is the entire population, which is the case in our study of two LRT routes and a limited number of station areas (see Bennett 1985). In this paper, the case application example shows how ANP facilitates an analysis of land use and transportation as elements of an urban system with feedback with data parsimony in the ex ante estimation of site-specific, spatial-economic impacts. A brief introduction to ANP is given comparatively with AHP following. Additionally, a brief comparison of ANP in relation to the commonly used methods of Markov chains and graph theory is provided in the appendix.

A step-by-step introduction of ANP and AHP methods is given comparatively. The introduction contains two simplified examples: a bridge selection with safety and aesthetics as criteria, and an LRT route selection with density and land use mix as criteria. The simplified examples highlight how ANP makes intuitive sense in multicriteria evaluation of systems with feedback.

\section{The Analytic Network Process}

A bridge evaluation example: Consider a simple example of selecting the best bridge (Saaty 2003). Problem data: two selection criteria, safety and aesthetics, are used with safety being strongly preferred to aesthetics. Attributes of alternatives: Bridge A is safe and beautiful; Bridge $\mathrm{B}$ is safer but ugly. Which bridge is ideal, given both the extreme importance of safety relative to aesthetics and the features of the alternatives? Let us approach this problem with two methods: AHP and its general form, ANP. The answer depends on which method is used. As shown below, the AHP answer is Bridge $\mathrm{B}$, since safety is given a high priority. However, the ANP answer is Bridge $\mathrm{A}$, when nonlinearity is taken into account. Let us see which answer is closer to "common sense" (Saaty 2003).

First, let us examine the AHP approach to this simple problem. The AHP is a multicriteria evaluation/decision method that identifies and arranges the components of a complex problem into a hierarchal structure with multiple levels. It determines the influence of all of the elements measured from the top down, from the goal to the criteria to the alternatives. In our example, the goal of selecting the best bridge appears at the top of the simple hierarchy (figure $2 \mathrm{a}$ ). The two criteria (aesthetics and safety) are shown in the second level, and the two alternatives (Bridge A and Bridge B) are shown in the lowest level of the hierarchy. This is the problem-framing phase of AHP, which uses a hierarchy to structure a problem. The problemsolving, analytic phase involves paired comparisons of the factors to determine relative importance. Saaty's AHP method arranges the factors in a matrix and demonstrates that the characteristic vector (or eigenvector) solution is the best method of synthesizing (and thereby determining the relative weights) of the judgments that arise from all the paired comparisons (Saaty 1990, more on this below). Factors at the second level (criteria) are compared relative to the 
goal, and alternatives are compared relative to the criteria. In complex problems with multiple levels, the factors at each level are compared with respect to the factors at each previous level until a lowest level (that typically contains the alternatives) is reached. Finally, in the synthesizing step that determines the "global" weights of the elements in the hierarchy, the weights of the criteria are multiplied by the ratings of the alternatives and the results are calculated to determine the final scores of the alternatives.

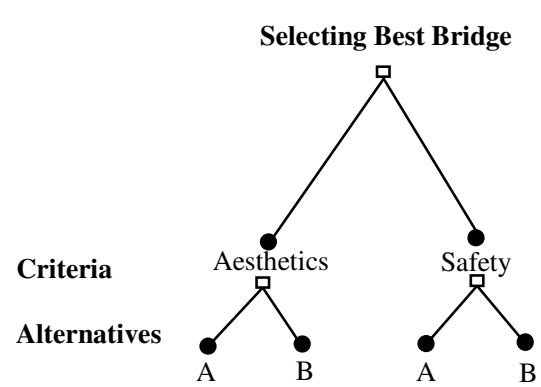

(a) Hierarchy

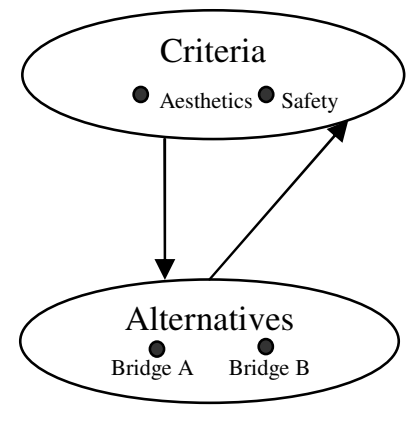

(b) Network

Figure 2: The bridge model shown in a hierarchy (a) and network (b) of criteria ("clusters", represented by ovals) and alternatives ("nodes", dots within clusters) with feedback.

The bridge example problem above is solved this way by AHP. The parried comparison of safety and aesthetics with respect to the goal of a safe bridge is indicated by the extreme importance of safety over aesthetics. This is noted by a value of 9 from the nine-point AHP scale explained below (table 1 on the following page). This first comparison produces the relative weights of the aesthetics $(0.1000)$ and safety $(0.9000)$ criteria (table 1$)$. More on the method of calculation is given below.

The AHP uses a 9-point scale of absolute numbers (Saaty 1987):

1. Equal importance (1) - the two activities contribute equally to the objective.

2. Moderate importance (3) —experience and judgment slightly favor one activity over another.

3. Essential or strong importance (5) - experience and judgment strongly favor one activity over another.

4. Demonstrated importance (7) — an activity is strongly favored and its dominance is demonstrated in practice.

5. Extreme importance (9) - the evidence favoring one activity over another is of the highest possible order of affirmation.

6. Intermediate values between two adjacent judgments $(2,4,6,8)$ —compromise is needed.

7. Reciprocals of the above numbers-if an activity $i$ has one of the above numbers assigned to it when compared with activity $j$, then $j$ has the reciprocal value when compared with 
$i$. Note that even finer numbers are used to compare elements that are close together. For example, alternatives with nearly equal importance could have values of $1.1,1.2, \ldots, 1.9$.

Table 1: Paired comparison of the criteria (aesthetics and safety) with respect to the goal (safe bridge) as well as the alternatives (bridges) with respect to the criteria.

\begin{tabular}{lccc}
\hline Goal: Safe bridge & Aesthetics & Safety & Weight $\left(w_{i}\right)$ \\
\hline Aesthetics & 1 & $1 / 9$ & 0.1000 \\
Safety & 9 & 1 & 0.9000 \\
\hline Consistency index $=0.0000$ & & $\sum w_{i}=1$
\end{tabular}

\begin{tabular}{lccc}
\hline Aesthetics & Bridge A & Bridge B & Weight $\left(w_{i}\right)$ \\
\hline Bridge A & 1 & 7 & 0.8750 \\
Bridge B & $1 / 7$ & 1 & 0.1250 \\
\hline Consistency index $=0.0000$ & & $\sum w_{i}=1$
\end{tabular}

\begin{tabular}{lccc}
\hline Safety & Bridge A & Bridge B & Weight $\left(w_{i}\right)$ \\
\hline Bridge A & 1 & $1 / 2$ & 0.3333 \\
Bridge B & 2 & 1 & 0.6667 \\
\hline Consistency index $=0.0000$ & & $\sum w_{i}=1$ \\
\hline
\end{tabular}

All that remains is the comparisons of the alternatives with respect to the two criteria (also shown in table 1). Recall the features of the alternatives noted above. The beautiful Bridge A is rated as far more preferable than the unattractive Bridge $B$ (value of 7 ). However, the quite safe Bridge $A$ is rated as equally to moderately more preferable than the safer Bridge $B$ (value of 2). Finally, the relative weights of the aesthetics (0.1000) and safety (0.9000) criteria are post-multiplied by the ratings of the alternatives for the criteria. The results are calculated to determine the final composite scores of the alternatives (table 2).

Table 2: Weighted linear summation method for determining the final scores of the alternatives.

\begin{tabular}{lccllc}
\hline Alternatives & Aesthetics & Safety & Criterion & Weight & Alternative Priority \\
\hline Bridge A & 0.8750 & 0.3333 & Aesthetics: & 0.1000 & $0.387(38.7 \%)$ \\
Bridge B & 0.1250 & 0.6667 & Safety: & 0.9000 & $0.613(61.3 \%)$ \\
\hline
\end{tabular}

The AHP identifies Bridge B as the better choice. Even though Bridge A is quite safe and beautiful as well, it receives a lower score relative to the safer but unattractive Bridge B. But if the two bridges are both safe, why would we not prefer the one that is also beautiful?

Now consider the same problem approached as a simple network with feedback (figure $2 b$ ). We will examine whether this alternative, nonlinear formulation is closer to our intuition. The criteria and the alternatives are shown as four connected "nodes" of a simple network. Unlike 
the linear hierarchical representation, in which the direction of causation is from the top down (i.e. from criteria to alternatives), in a network with feedback, the criteria and the alternatives are connected in both directions. The numerical example below captures the significance of this type of representation, which allows for comparisons of the nodes in order to determine the interactions and relative influence of all of the nodes in a network operationally using the mathematics of the ANP. We have already compared the alternatives with respect to the criteria. All that remains is comparisons of the criteria with respect to the alternatives (table 3).

Table 3: Comparisons of the criteria to determine the prevalence or dominance of the criteria in the alternatives for the bridge selection problem.

\begin{tabular}{lccc}
\hline Bridge A & Aesthetics & Safety & Weight $\left(w_{i}\right)$ \\
\hline Aesthetics & 1 & 6 & 0.8571 \\
Safety & $1 / 6$ & 1 & 0.1249 \\
\hline Consistency index $=0.0000$ & & $\sum w_{i}=1$ \\
& & & \\
\hline Bridge B & Aesthetics & Safety & Weight $\left(w_{i}\right)$ \\
\hline Aesthetics & 1 & $1 / 9$ & 0.1000 \\
Safety & 9 & 1 & 0.9000 \\
\hline Consistency index $=0.0000$ & & $\sum w_{i}=1$ \\
\hline
\end{tabular}

The prevalent feature of Bridge $\mathrm{A}$ is its aesthetics (beauty) compared to safety. This is indicated by the strong to very strong importance or dominance of aesthetics (value of 6) over safety for Bridge A. For Bridge B, the predominant feature of safety is indicated by the extreme importance or dominance of safety (value of 9 ) compared to aesthetics. It is natural to expect that the perception of the features of the bridges will influence selection preference criteria. To measure the influence of the criteria on the alternatives, as well as the alternatives on the criteria, we form a "supermatrix" (table 4).

Table 4: Supermatrix showing weights of the alternatives and criteria for the bridge example in a simple network from Figure $2 b$.

\begin{tabular}{llcccccc}
\hline \multirow{2}{*}{ Cluster node names } & \multicolumn{2}{c}{ Alternatives } & & \multicolumn{2}{c}{ Criteria } \\
\cline { 3 - 4 } \cline { 6 - 7 } Alternatives & Bridge A & 0 & 0 & & 0.8750 & 0.3333 \\
& Bridge B & 0 & 0 & & 0.1250 & 0.6667 \\
\multirow{2}{*}{ Criteria } & Aesthetics & 0.8571 & 0.1000 & & 0 & 0 \\
& Safety & 0.1429 & 0.9000 & & 0 & 0 \\
\hline
\end{tabular}

The row and column headings simply list the alternatives and criteria, and the columns contain the computed relative weights from table 1 on the preceding page and table 3 . The supermatrix is the operational method of determining the impacts of weights of the alternatives on the weights of the criteria. A similar set of impacts is determined for the effect of the criteria 
on the alternatives by simply multiplying the supermatrix by itself repeatedly. (The first row is multiplied by the first column, second row by the second column, and so on, until all of the supermatrix entries are weighted). This procedure is tantamount to raising the supermatrix to powers. The stopping point or limit for the row-by-column multiplication process is reached when all of the columns are identical (i.e. when the priorities are obtained from any column of the supermatrix; more on the mathematics of ANP below). The ANP results for the bridge example are shown in table 5, which identifies the beautiful and safe Bridge A (32.8\%) as the better alternative to the safe but unattractive Bridge B (17.2\%).

This example highlights the contrasting features of AHP and ANP. The AHP allows the weights of the criteria to be adjusted for new information, and it even provides an indicator (consistency index) of when it is desirable to reassess the weights of the criteria. The ANP allows us to go one step further-the alternatives, like new or additional alternative-specific pieces of information, determine the weights of the criteria. Alternatives in various contexts influence the criteria differently according to ANP. Therefore, ANP provides a context-specific multicriteria evaluation method that allows for the measurement of one unique alternative in the face of general criteria.

Table 5: Limit supermatrix showing weights of the alternatives and criteria for the bridge example in a simple network from Figure $2 b$.

\begin{tabular}{llcccccc}
\hline \multirow{2}{*}{ Cluster node names } & \multicolumn{2}{c}{ Alternatives } & & \multicolumn{2}{c}{ Criteria } \\
\cline { 3 - 4 } Alternatives & Bridge A & 0.3284 & 0.3284 & & 0.3284 & 0.3284 \\
& Bridge B & 0.1715 & 0 & & 0.1715 & 0.1715 \\
\multirow{2}{*}{ Criteria } & Aesthetics & 0.2986 & 0.2986 & & 0.2986 & 0.2986 \\
& Safety & 0.2013 & 0.2013 & & 0.2013 & 0.2013 \\
\hline
\end{tabular}

The relative importance of the criteria is determined independently from the alternatives in $\mathrm{AHP}^{2}$

This follows from an axiom of AHP stating that the hierarchy levels are independent (for a thorough discussion of the axioms of AHP, see Saaty 1986). A hierarchical model structure

\footnotetext{
${ }^{2}$ The admission of student candidates to schools (with GPA, GRE score, statement of goals, and similar criteria) or tenure or promotion evaluation of professors and staff(with teaching, research, and collegiality) provide examples of criteria considered as independent from the alternatives. In cases like these, when either the number of alternatives is large (as in an applicant pool for school admission) or the criteria are treated as fixed standards, the rating mode of the AHP is used instead of the paired comparison mode. The relative importance (or weight) of the criteria is determined by the paired comparison method of the AHP and may be used as a formulaic standard. The alternatives (candidates) are rated individually against the criteria. The rating score is weighted by the relative importance of the criteria, and the total score of each alternative is determined. Table 2 on page 92 shows in detail the AHP calculations for the bridge example corresponding to the hierarchy model in Figure 2a. The discussion of contrasting features of the AHP and ANP with additional examples (e.g. land suitability or LRT route evaluation) indicates the desirability of the nonlinear ANP over the linear AHP. This is particularly true in situations where criteria are not independent of the alternatives. The general form of AHP - ANP — provides a better technique in situations where the criteria are not ubiquitously held as standards; in these cases, the global criteria are determined jointly with the local, contextor site-specific alternatives. For a conceptual discussion distinguishing the terms idiographic (case-specific) and nomothetic (law-like) in spatial analysis, see Bennett and Thornes (1988) and Brown (1988, 1991).
} 
makes intuitive sense, because by definition one begins with the "abstract" goal (top) and ends with the "concrete" alternatives (bottom) in a hierarchy. However, in situations where the goal or criteria are dependent upon the alternatives, a network model structure, with feedback from the alternatives to the goal and criteria, is desirable (figure 2b). An example of this situation is a land suitability analysis, where a land unit (as an alternative) determines site-specific suitability criteria (i.e. where the overall suitability criteria are partly determined by land unit spatial characteristics) (see also Malczewski 1999). In the nonlinear ANP, the relative weights of the criteria affect alternatives; these alternatives in turn affect the criteria. In the linear AHP, the relative weights of criteria determine the score of the alternatives independent of the influence of the alternatives.

Consider an example closer to the case analysis in this paper. The density and land use mix are among the criteria considered in choosing between two possible LRT routes A and B, with density generally regarded as more important than land use mix. Suppose both routes meet the density threshold criterion for an LRT, and that route A serves residential and commercial areas with a better land use mix than areas served by route B. Land use mix, which is considered a desirable site area feature for the LRT route, is more prevalent in route A than route B. If both routes meet the critical density requirement, it is logical to expect that the better choice is the one that also provides a desirable land use mix. Intuitive calculations of this sort are facilitated by ANP. This example also indicates how the site-specific information is used in an ANP application-the site-specificity does not arise merely from local data used to verify universal phenomena, as is the case in a deductive methodological approach. Economic and spatial factors, generally identified in literature as interrelating impacts of land use and urban transportation, are used in this case study to define or frame the universal elements of a land use/transportation network. This problem-framing or problem-structuring phase characterizes the case study approach as a deductive process. However, the feedback aspect of this network formulation allows for the site-specific assessment (rating) of factors in such a way that it captures the impact of the particular site-specific or local characteristics on the universal elements. This problem-solving phase characterizes the ANP approach as an inductive process, much like the example above, where a particular bridge influences the weights of the general criteria, and the final weights or priorities are obtained from the interrelationship of the general and particular system elements. The ANP used in the case analysis below facilitates a simultaneously deductive and inductive systems approach.

A square matrix is the basic AHP procedure for comparing factors and determining their relative importance. In general, matrix $A=\left(a_{i j}\right)$ is positive $a_{i j}>0$ and reciprocal $a_{j i}=1 / a_{i j}$. All of its diagonal elements are set to one $a_{i i}=1$. The coefficients of this matrix are determined by comparing pairwise the weight of the criterion or element $C_{i}$ with weight of criterion or element $C_{j}$, thus forming a matrix of ratios $a_{i j}=w_{i} / w_{j}$ for all of the criteria $C_{1}, \ldots, C_{n}$.

The judgments of the paired comparisons can be synthesized in various ways, such as the normalized row-average method. For numerical examples, see the paired comparisons that determine the criteria weights in the bridge example (table 1 on page 92). The normalization of row averages provides an approximation to the characteristic value (or eigenvalue) solution (for an explanation of the alternative methods of estimation, see Saaty and Vargas 1982). However, the eigenvalue method provides the more precise or "robust" solution regardless of matrix size and inconsistency of judgments that vary with the order of the matrix of paired comparisons (Saaty 1996a). Rogers (1971, p. 405) noted that several problems in urban and regional analy- 
sis call for the solution of the following system of linear equations. The characteristic value (or eigenvalue) problem is $A w=n w$, where $A$ is a matrix that is post-multiplied by a column vector $w$, and the result is proportional to $w$, and $n$ is a scalar factor. In the system of linear equations $A(I-n) w=0, A$ is known and we solve for the unknowns $w$ and $n$. $A$ has unit rank, and all of its eigenvalues $\lambda i, i=1, \ldots, n$ except one are zero $\left(\lambda_{\max } \neq \lambda_{i}=0\right)$. The sum of all of the diagonal elements of $A=\left(a_{i i}=1\right)$ (i.e. the trace of $\left.A\right)$ is denoted by $\sum \lambda_{i}=\operatorname{tr}(A)=n$. The system above is thus restated as $A w=\lambda_{\max } w$. The solution $\mathrm{w}$ is recovered from any column of $A$; columns in $A$ differ by a multiplicative constant. Upon normalization of the columns of $A$, a unique solution $w$ is obtained regardless of the column used. This also ensures that $\sum w_{i}=1, i=1, \ldots, n$.

Contributing to the wide-ranging applications of the AHP are practical problems that involve the measurement of intangibles, and problems that include mixed qualitative and quantitative criteria. Compared to other multicriteria methods in the literature (e.g. Nijkamp and Voogd 1983; Yoon and Hwang 1995), AHP is a viable alternative to the measurement of intangibles since intangibles by definition do not have known units (Saaty 1994). However, Saaty (1996b) remarked that the paired comparison method is a natural way of assessing utility, even in problems with known scales and known variable values. For example, to a low-income traveler, a $\$ 20$ trip by car may be much more expensive that a $\$ 10$ trip by transit; to a high-income traveler, however, the cost differential may be large but not perceived as important. Similarly, the conceptual affinity with "satisficing" or bounded-rationality, instead of utility-maximizing behavior, contributes to the popularity of AHP particularly in transportation applications (e.g. Banai-Kashani 1989). This follows from the logic of a cognitive limit for the number of factors $\mathrm{n}$ that are compared $\frac{1}{2} n(n-1)$ in a reciprocal matrix of size $n$ gauged with a consistency index. The limit on the size of the paired comparison matrix $(n \leq 9 \pm 2)$ and the associated consistency index confirm the results from psychological experiments on the number of pieces of information that can be processed before one gets confused (see also Miller 1956; Simon 1981, 1983). Saaty (1980) showed that the value of random consistency $\bar{I}$ increases when the size of the paired comparison matrix is increased (i.e. with the number of factors $n$ in the paired comparison matrix; more in next subsection below; see also Saaty 1980). However, AHP fills a void in evaluation methods: 1) with a framework for the analysis of a problem with interrelated parts (i.e. a hierarchy or network) and 2) with a measure of consistency with which the parts are assessed. The problem of consistency in the paired comparison matrices is discussed next before the structural properties of AHP are described.

\subsection{The calculus of consistency}

When the elements are known tangible quantities (e.g. weight, length, etc.), the matrix of ratios that contains the relative weights of the elements $A$ is consistent; logically, if $A_{i}$ is better than or preferred to $(>) A_{j}$ and $A_{j}>A_{k}$, then $A_{i}>A_{k} . a_{i k}=w_{i} / w_{k}, a_{i j}=w_{i} / w_{j}, a_{j k}=$ $w_{j} / w_{k}$. With consistency, $a_{i k}=a_{i j} a_{j k}$ for $i, j, k=1, \ldots, n$. With inconsistency, however, $a_{i k} \neq a_{i j} a_{j k}$. It turns out that $\lambda_{\max } \geq n$ always (see Saaty 1980). The closer $\lambda_{\max }$ is to $n$, the better the consistency of the parried comparisons. This gives rise to a measure of consistency with an index $I=\left(\lambda_{\max }-n\right) /(n-1)$. This index is compared to its average value determined in a large sample of size 500 of randomly generated reciprocal matrices of the same size as $A$. The comparison $R=I / \bar{I}$ indicates whether the estimates of the relative weights are closer to 
being logically consistent or closer to being random (Saaty 1987). An upper limit of 10 percent indicates a measure of good consistency (see Saaty 1980).

\subsection{From hierarchy to network structure}

In a typical AHP, the goal and objectives are represented at the top of a hierarchy and the alternatives are represented at the lowest level (as in figure 2 on page 91). The priority (i.e. sum normalized to unity) of the $i$ alternatives $P_{i}$ with respect to the $n$ criteria is determined by means of the principle of hierarchic composition with a linear weighted summation method. The weights of the criteria $w_{k}$ are multiplied by the scores or ratings of the $m$ alternatives with respect to all $k$ criteria $A_{m k}$, and the results are calculated to obtain the overall priority of the alternatives $P i=\sum w_{k} A_{m k}$ for all $k=1, \ldots, n$ and $m=1, \ldots, m$.

In figure 2 on page 91, the two criteria and the two alternatives form four "nodes" of a "control" system or network. In the standard AHP, the priorities of the alternatives are derived from the weights of the criteria. However, since alternatives also influence the criteria, and criteria in turn influence alternatives (i.e. since the system has feedback), the final priorities of the alternatives are obtained from both the criteria and the alternatives. In the bridge example above, the priorities are determined from all four nodes of the system.

The relative importance of the alternatives relative to the criteria is determined through paired comparisons as in the standard AHP (see table 1 on page 92 . However, the alternatives are rated relative to the criteria, and the weights of the criteria are themselves determined independently from the alternatives. In ANP, an additional step is taken to establish the impact of an indirect link (in our example, feedback from the alternatives to the criteria). In this second step, the relative importance (or weight) of the criteria is determined with respect to a specific alternative. The prevalence of the criteria in the alternatives is thus determined. In other words, the criteria are treated as alternative-dependent in the second step, instead of alternativeindependent as in the first step.

Just as in AHP, the criteria-dependent step in which we perform paired comparisons of the alternatives (e.g. Bridge A and Bridge B) with respect to the criteria results in two column vectors shown in the two columns under the alternatives cluster of the supermatrix (table 4 on page 93). For the alternative-dependent step, the hallmark of ANP is the paired comparison of the criteria with respect to the alternatives; this step produces two column vectors in the columns of the supermatrix under the criteria cluster. Note that the table entries containing zeros indicate the independence of the inner nodes of the clusters. Otherwise, the cluster is shown graphically with a loop, and the nonzero elements are calculated to determine the relative importance of the nodes. The loop indicates competition among the vendors. (The "hamburger" model provides an example in Appendix figure A.1 on page 111; see also Saaty 2003). The case analysis below (Section 3, figure 3 on page 99) is framed in a similar manner to this example, which aims to determine the market impact share of two LRT route alignment alternatives that are considered mutually exclusive.

The computations are made operational in supermatrix $W$. The columns of this matrix contain the weights of the nodes of the clusters, and the relative importance of the clusters is determined though paired comparisons. Our goal is to make $W$ column stochastic (i.e. the column sum is one). Multiplication of $W$ by the cluster weights (which are also column stochastic) provides the intended result of a stochastic $W$. The final step is to determine the 
global weights of all of the nodes in the network; this is achieved by increasing powers $k$ of $W_{k}=\lim W_{k}, k \rightarrow \infty$. The overall priorities are given from any column of $W_{k}$. Here the introduction to ANP is given with a simple example and with limited mathematics (for a thorough mathematical exposition of ANP, including its definition, concepts, theory, and method of priorities in systems with feedback, see Saaty 1996b). A brief discussion of the conceptual and methodological affinity of ANP with Markov chains and graph theory is provided in the Appendix.

The scaling method in ANP with absolute priority weights-such as probability—provides flexibility in the measurement of diverse but interdependent system elements of a unified land use/transportation system. This is in contrast to the simple categorical (0-1 designation) or interval-scaled methods of graph theory (see Appendix). Furthermore, statistical methods commonly used to measure impact in the urban system assume independence in the face of interdependent of the system elements. More importantly, in the small area problem like the case described in this paper, relational spatial data at the parcel level provided a sample that consisted of the entire population of parcels (see also Bennett 1985). The interdependence of data invalidates the assumption of statistical independence. Parcels are not drawn randomly as if they are statistically independent, as in the relative-frequency view of probability. However, applying probability methods to the urban system or subsystem appeared in the near-classic approaches by Chapin and Weiss (1968) and Huff (1963) that described shopping center trade areas or the growth in the residential areas (see also Chapin and Kaiser 1979). These studies are considered precursors to the recent models of urban systems in the larger scale of the cityregion, e.g. with cellular automata that is used in combination with multicriteria methods like AHP, noted above.

Statistical and probability methods are useful when historical data are available for empirical observation and parametrical estimation. They are limited when there is a structural transformation or when past observation is no longer sufficient for the prediction of future system performance (e.g. after the introduction of new modes or technologies). The limitations are addressed by means of a proxy in transportation; for example, a nonstop or express bus on an exclusive right-of-way provides a proxy (ex-post) for an LRT route and is thus used to estimate impacts (ex-ante). However, the ex-post/ex-ante analytical tension remains. Similarly, the deductive/inductive or universal/particular tensions exist in analysis due to the unique nature of the conditions specific to a given place in the face of a universal phenomenon.

Land use and transportation epitomize a system or network with feedback and thus offer a plausible application for ANP. Diverse applications of AHP/ANP to planning, design, evaluation, alternative selection, and location/allocation problems provide remarkably accurate predictions of political, economic, and even sports outcomes. (Niemira and Saaty 2004; Saaty and Vargas 2001; see also the collection of papers from a recent symposium on AHP/ANP, Levy and Saaty 2005). In the next section, an application of ANP to the problem of LRT alternative route selection is presented. The ANP determines which of the two LRT route alignment alternatives is better when land use and property value impacts on station area neighborhoods are among the multiple influencing factors. The findings should inform public discussion from the perspective of impacted quarter-mile station area neighborhoods, thereby influencing a desirable public policy decision on the city's LRT alignment choice. 


\section{Determining market impact share of LRT route alternatives with ANP}

Figure 3 illustrates a network with land use, property value, redevelopment potential, etc., and LRT route alignment alternatives as clusters. This network with feedback among the clusters (or factors) and nodes (or sub-factors) is used to determine the "market impact share" of two route alignment alternatives. The case application is limited to only two alternatives because that is the actual number of alternatives currently under consideration in the city. Furthermore, if desired, the "no-build," "do nothing," TSM, or still others could be assessed and added as additional alternatives. Previous AHP studies include examples of this kind of evaluation as well (Banai 2006). This network model is conceptually analogous to the determination of market share in a consumer economy (Saaty 2003 and Appendix; see also Khasnabis and Chaudhury 1994). A notable difference is in the absence of a loop in the alternative routes cluster, since the alternatives are regarded as mutually exclusive, compared to the market share model in Appendix figure A.1 on page 111 in which the alternatives are treated competitively, with interdependence indicted with a loop. The better LRT route alternative is identified by the "market share impact" in a network of land use/transportation with interactions. This term is used to describe which of the two LRT route alignment alternatives has the greater share or proportion of impact, determined by the interactions of all the factors and sub-factors of the network. A GIS with parcel-level land use attribute data in the public domain (e.g. tax assessment) provides inputs for the site-specific assessment of impacts in ANP.

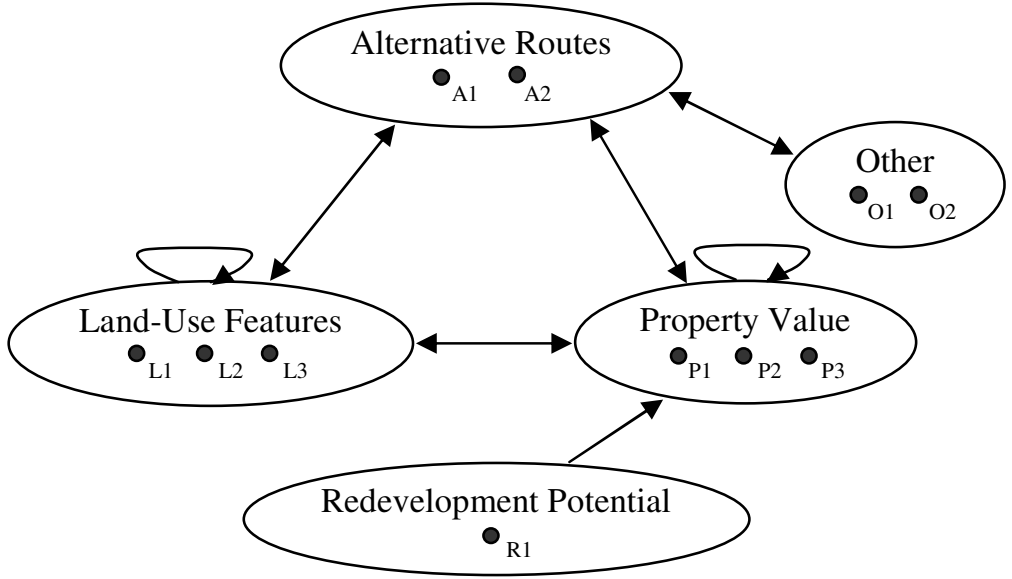

Figure 3: Route alternatives market impact share network.

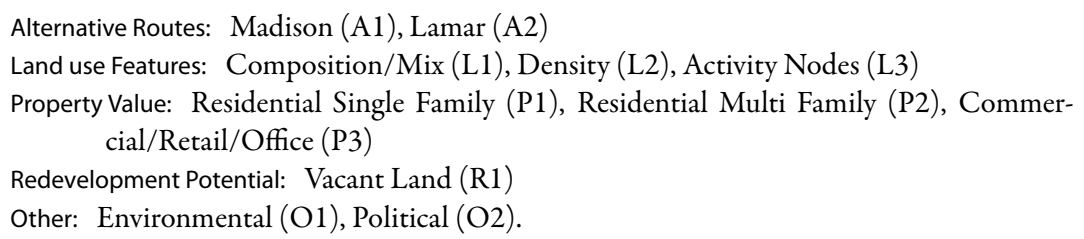

Note that the alternative routes cluster has two nodes (route alternatives) with no "buckle" or loop, since as noted above the route alternatives are considered mutually exclusive (figure 3 ). However, the land use and property value clusters contain nodes with interactions indicated with loops. The land use cluster, for example, contains three nodes called activity nodes, density, 
and composition/mix. The procedure for the estimation of the weights of the network clusters and nodes to determine the optimal route, i.e. the LRT route with greater "market impact share" is summarized as follows.

First, the clusters are compared in order to determine their relative influence in a network of five clusters (figure 3 on the previous page). This step produces a column stochastic cluster weights matrix (column sums are one) that contains relative weights. Second, the nodes in each cluster are compared, andthe comparisons are repeated for all nodes of the related clusters of the network and in deference to the direction(s) of causation. The relative weights of the nodes are determined for all the clusters. A supermatrix contains the weights for all cluster nodes. Third, the weights of the nodes that were just determined are weighted by the cluster weights (from first step) in a weighted supermatrix. Finally, the limit supermatrix is computed. When the clusters in a network are considered equally important, their weights are determined by the "default value" of $1 / n$, where $n$ is the number of the nodes under each cluster in the software for ANP, SuperDecisions (Saaty 2003). However, the five clusters in the network of figure 3 contribute to the market impact share of the LRT alternatives with varying magnitudes of influence. To determine their relative influence the clusters are compared. The clusters are identified from a vast literature of the interrelationship land use and urban public transportation, ranging from physical and economic to political and environmental impact of LRT $^{3}$; however, the factors are rarely considered simultaneously in a unified analytical framework.

Furthermore, the clusters shown in figure 3 on the preceding page are commonly studied in one-way analysis of impacts. For example, the two-way relation between LRT alternatives cluster and property value cluster in our network approach (figure 3) commonly appear separately in the studies of the LRT impact on property values, and of the impact of property type (e.g., residential, commercial, office, etc.) on LRT ridership. The importance of the political and environmental factors in land use and transportation planning and evaluation is realized. However, owing to the intangible qualities, they are either assumed away or considered exogenously in the standard quantitative methods commonly used to determine the land use impact of transportation. In contrast, they are considered endogenously in the land use/transportation network, impacting LRT alternative routes qualitatively, which in turn impact land use features and property values quantitatively. The ANP facilitates land use/transportation system evaluation with both qualitative and quantitative attribute data. There are four variables with reciprocal relationships; only one factor (redevelopment potential) maintains a one-way relationship

\footnotetext{
${ }^{3}$ Parcel-level GIS facilitates determination of the station-area neighborhood activity nodes, density, composition and mix as factors quantitatively. Paired comparisons can be made by forming ratios of the raw numbers and entering values directly in the matrix of paired "marginal" comparisons. However, the "likely" mode of the ANP rating scale permits assessment of factors with relative priority scale reflecting the uncertainty in the estimation of likely impacts in the absence of precedent. The likely mode is justified logically when ANP is used in ex ante estimation and prediction in the face of limited observation. Diverse applications of AHP/ANP to planning, design, evaluation, alternative selection, and location/allocation problems provide remarkably accurate predictions of political, economic, and even sports outcomes (Niemira and Saaty 2004; Saaty and Vargas 2001). See also the collection of papers from a recent symposium on AHP/ANP (Levy and Saaty 2005). Remarkably, when used in prediction in wide ranging applications, ANP/AHP results are validated when data and information are made available later (Saaty 1998). With reference to "validation exercises" Saaty (2007, p. 1) concludes that “...judgments using the Analytic Hierarchy Process can match objective measures rather closely." The "validation exercises" with AHP/ANP thus "build confidence that our judgments can give good results when objective measures are not available." The case analysis in this paper confirms this observation. A cost-benefit analysis $(\mathrm{B} / \mathrm{C})$ replicated the results of the ANP model and identified Madison Avenue as the better alternative.
} 
in the network. The nonlinear network approach in our simplified case application of ANP fills a void in the literature with a systemic analysis of land use/transportation elements with interaction quantitatively and qualitatively. However, in the process of determining the relative influence of the network elements through the ANP scale and method of paired comparisons, we draw upon the existing literature as prior knowledge, in addition to "local" knowledge that reflects the particular or site-specific conditions. In short, our approach is both deductive and inductive. The (network) systems approach is a synthesis of previous studies considered in a unified framework of the site-specific case study. For example, in the comparison of the two clusters "land-use features" and "property value", the following typical question is posed: Which cluster influences the market share of the LRT alternatives more-land use features or property value? The nine-point scale of ANP explained above is used to quantify the judgment of relative influence. Examples of specific values and their justifications are given in figure 4 on page 104.

When all the interrelated clusters are compared and rated, the resulting relative importance is shown compactly in a cluster weights matrix in table 6 (as in table 4 on page 93 in the bridge example, displaying the weights of the alternatives and the criteria). The cluster weights matrix is column stochastic (its column sums are one). If multiplied by a supermatrix in which the weights of the cluster nodes are contained (step 2 and 3 outlined above), the resulting clusterweighted supermatrix is also column stochastic. In the interest of brevity, the result of the multiplication is shown after it is raised to powers, concluding with the limit supermatrix in which all the columns are identical (table 7 on the following page, as in table 5 in the bridge example) (for a discussion of the limitations of this rule, see Saaty 1996b). The cluster node weights are obtained from any column of the limit supermatrix (table 7).

Table 6: LRT market share: Cluster weights matrix

\begin{tabular}{llllll}
\hline Cluster & $\begin{array}{l}\text { Alternative } \\
\text { routes }\end{array}$ & $\begin{array}{l}\text { Land-use } \\
\text { Features }\end{array}$ & $\begin{array}{l}\text { Property } \\
\text { value }\end{array}$ & $\begin{array}{l}\text { Redevelopment } \\
\text { potential }\end{array}$ & Other \\
\hline 1. Alternative routes & 0 & 0.285714 & 0.285714 & 0 & 1 \\
2. Land-use features & 0.102856 & 0.571429 & 0.571429 & 0 & 0 \\
3. Property value & 0.57533 & 0.142857 & 0.142857 & 1 & 0 \\
4. Redevelopment potential & 0 & 0 & 0 & 0 & 0 \\
5. Other & 0.321813 & 0 & 0 & 0 & 0 \\
\hline
\end{tabular}

The paired comparisons of the cluster nodes (for example, land use features) in a matrix with respect to an alternative route cluster (Madison and Lamar) determine the prevalence or dominance of the land use features in the alternative routes cluster (figure 4 on page 104). This kind of comparison is contextual, or site-specific, and responds to a direction of causation that flows from the alternative routes to the land use cluster (figure 3). This is similar to the bridge example above. For example, the justification for the ratings of Madison Avenue is stated thus (figure 4a). The Madison line is slated to serve medical and shopping centers, here referred to as "activity nodes." Activity nodes are dense and have good composition/mix of their land uses. The factors of activity nodes and density as well as density and composition/mix are jointly determined by a rating value of two (see footnote 3 ). This rating indicates that dense places in Madison are equally to near-moderately likely to be places with a good land use composition/mix. However, the composition/mix are moderately to strongly likely (i.e. have a rating 


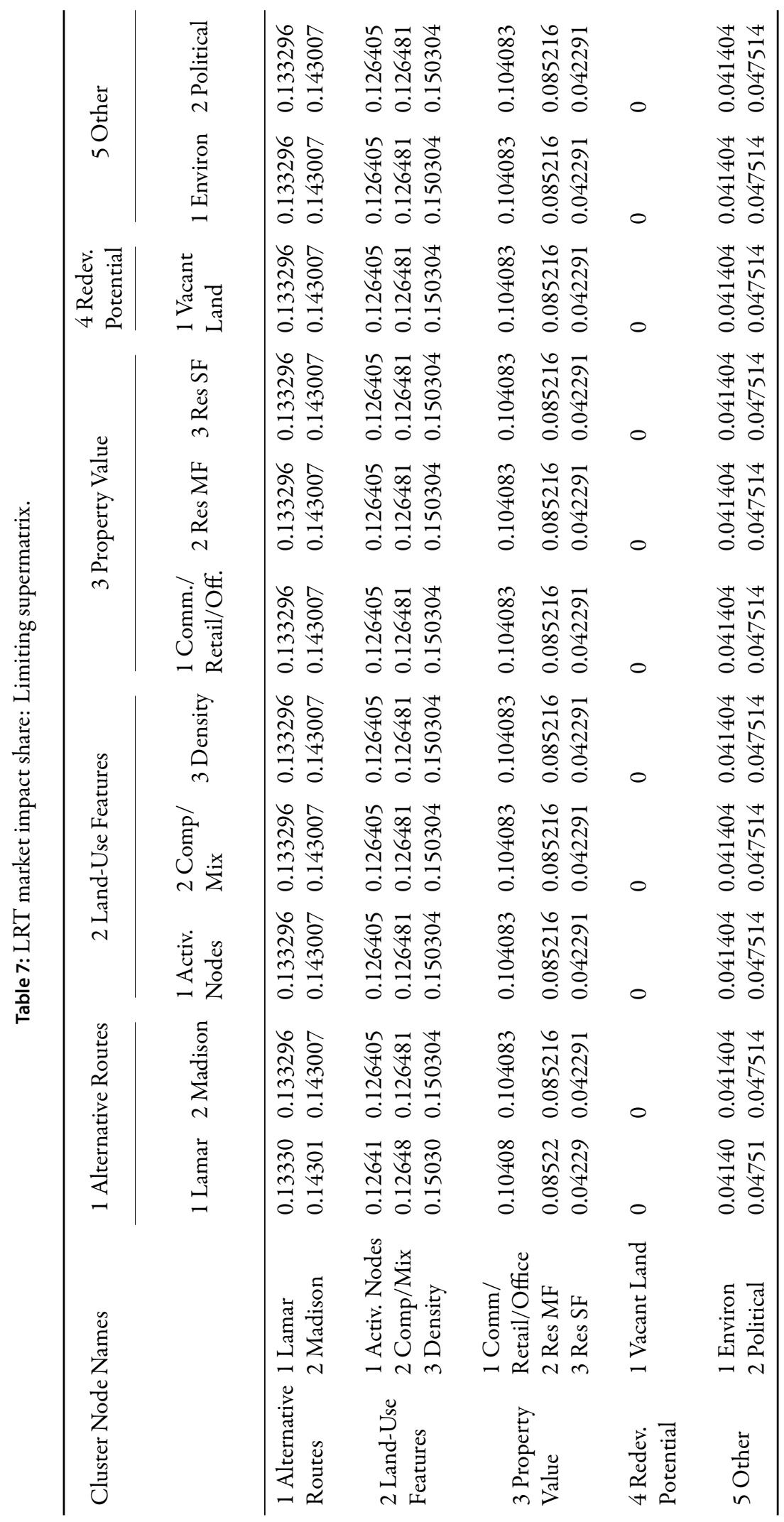


value of 4) to be determined by presence of the "activity nodes" for Madison. This is tantamount to an observation that activity nodes in Madison Avenue are a near-strong (scale value 4) indication of land use composition/mix. The justification for the ratings of Lamar Avenue can be stated with similar logic.

Conversely, for the direction of causation that flows to the alternative routes cluster, the paired comparisons of route alternatives are determined using the relative importance of the elements of the land use cluster as criteria (figure 3). The comparison of two nodes (Lamar Avenue and Madison Avenue) in the alternative routes cluster regarding the composition/mix node of the land use cluster is shown in Figure 4b. Madison is rated as moderately more likely (value of 3) than Lamar. The justifications for this rating draw upon the observation of the land use mix, which is only moderately more prevalent in Madison Avenue than Lamar Avenue. The nine-point scale values from equal (1) to most important (9) are shown with dialogue boxes in Figures $4 \mathrm{a}$ and $4 \mathrm{~b}$ with ANP software (for an introduction to SuperDecisions software for decision making with dependence and feedback, see Saaty 2003). The software incorporates the fundamental AHP scale, which allows for variable data input. Raw data values are flexible, either entered directly or alternatively scaled to provide a meaningful assessment of preference, utility, probability, or likelihood in the face of nonlinearity. The flexibility is helpful particularly in the comparisons of the alternative routes with intangibles and tangibles, as in assessment of the relative influence of the political and environmental factors in the "other" cluster of the network (figure 3). The influence of intangibles (e.g. local political support that favors one alternative route over another)is compared to the influence of tangibles (e.g. which alternative route has less impact on the environmentally sensitive station areas along the LRT routes) and is assessed with the facility of the scaling method.

A network with feedback thus determines the relative weights from all of the elements as clusters and nodes. When providing justifications for the ratings, local, site-specific conditions are considered together with knowledge of the space-economic impact of LRT from surveyed literature. We developed a questionnaire with a comment section in which the ratings with justifications could be recorded; this questionnaire permitted desired modifications of the ratings to be made in the subsequent application of the ANP. Applied in a survey framework, the questionnaire responses provide the ratings observations for further statistical analysis of consensus weights.

Property value is the largest impact ( 0.57533 ) of the alternative routes (column of table 6 on page 101) in comparison to land use features $(0.102856)$ and other (environmental and political) factors (0.321813). The results reflect the relative importance of property value when describing the impact of LRT among the land use factors in literature (e.g. Cervero 1994; Cervero and Landis 1993). The greater weight of the other (environmental and political) factor in comparison to the land use features is noteworthy. Findings in the literature similarly highlight the neighborhood effects of LRT that are perceived differently both politically and environmentally in different neighborhoods (e.g. Nelson 1999; Weinberger 2001).

Although Lamar Avenue is not far behind, Madison Avenue was found to be the better route for LRT due to its greater market impact share (table 7 on the preceding page). The relative weights of the remaining cluster nodes provide additional insight. Density has a greater weight than either activity nodes or composition/mix in the land use cluster, and the results corroborate the relative importance of density among the land use impacts of the LRT route. With respect to property value, commercial/retail/office is of greater importance than either residen- 


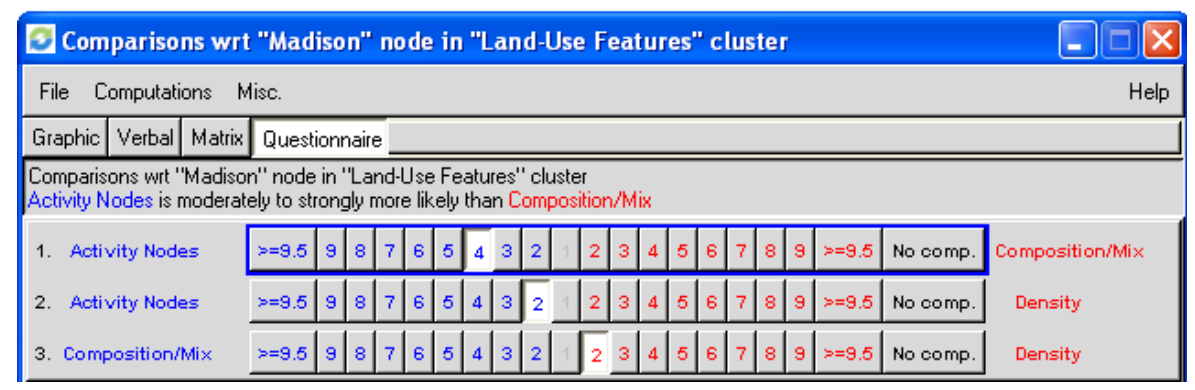

(a) Ratings of land use features, activity nodes, composition/mix, and density with respect to alternative routes (Madison Avenue).

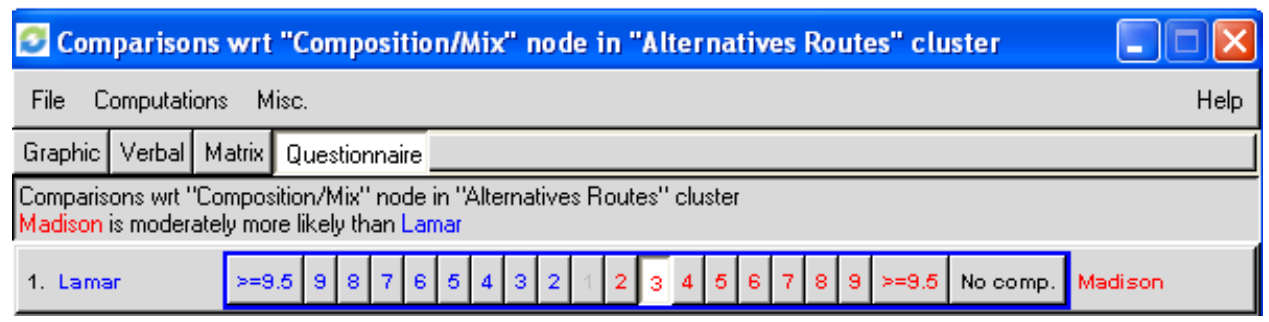

(b) Dialogue box for the comparison of the two alternatives with respect to the "composition/mix."

Figure 4: Comparison of alternative routes using ANP software.

tial multi-family or residential single family. The impact of rail transit on property value near station areas is studied in substantial literature, and these results are comparable to the findings in the literature. ${ }^{4}$ Finally, the intangible environmental and political factors in the other cluster are nearly equal in importance in this site-specific case. Whether the greater marginal weight of the political (0.0475) versus environmental (0.0414) criteria tips the final route selection decision in favor of either alternative remains to be seen, particularly since the overall impact of the factors reveals a marginal difference in the score of the two alternatives (Madison Avenue = $14.30 \%$ and Lamar Avenue $=13.33 \%$ ). A cost-benefit analysis replicated the results of the ANP and chose Madison Avenue as the better route alignment alternative for LRT. This finding is not surprising in the light of the greater relative weights of land use features and property value in the ANP; these factors are also included in a cost-benefit analysis. However, ANP results are derived from a set of factors that include intangibles that defy monetization in a standard cost-benefit analysis. Furthermore, the microscopic, site-level analysis of the spatial-economic impacts performed with ANP using limited data overcomes a shortcoming of cost-benefit analysis - as well as of predictive or evaluative methods commonly used in LRT station area impact assessment-which is constrained by the availability of data at the macroscopic regional level.

\footnotetext{
${ }^{4}$ For example, see Armstrong (1994); Cervero (1994); Cervero and Duncan (2002a,b); Cervero and Landis (1993); Dean and Smith (1993); Diaz (1999); Dueker and Bianco (1999); Price Waterhouse Coopers (2001); Transit Cooperative Research Program (2004); Weinberger (2001); Weinstein and Clower (1999). For a discussion of transit planning as both a technical and political process, see Wachs (1985).
} 


\section{Conclusions}

Literature identifies the wide-ranging impact of urban public transportation, from physical and economic to political and environmental. These impacts are a mixed bag of tangibles and intangibles with interactions, which pose limitations for commonly used methods, whether in the predictive or evaluative, ex ante or ex post variety. Furthermore, factors are rarely considered simultaneously in a unified analytical framework with feedback. By accounting for the interdependencies among land use and transportation as elements of a unified system with feedback, ANP provides an alternative method for determining optimal LRT route alignment when the impact criteria contain both tangible and intangible factors with interaction.

The system elements are compared and their relative importance determined by using the fundamental nine-point scale of AHP/ANP with absolute numbers. This makes it possible to assess elements with either no underlying scale (intangibles) or with incomplete information without imposing arbitrary units in measurement. The route alignment alternatives are expressed in proportions - like probability — which facilitates the interpretation of relative weight in context. The formulation of land use and transportation as elements of an interdependent system, as well as the measurement of the relative weights with the paired comparison matrix method, allow ANP to overcome a limitation of probabilistic and statistical methods used in systems evaluation. The latter methods require independence when the goal is to account for the interdependence of the system elements; this is characterized by the network model of the case study.

A questionnaire with examples of paired comparison matrices from the ANP software screen display facilitated the interactive and systematic assessment of the clusters and nodes. The consistency of the paired comparisons is shown together with the eigenvector matrix solution for further deliberation when the consistency index exceeds 10 percent (the acceptable threshold). Similar to the case comparison method noted above, ANP provides case- or sitespecific assessments of the relative systemic impacts of land use and transportation. In-depth estimates of the impacts' orders of the magnitude provide a logical area for further analysis. Systematic comparisons using a similar ANP-aided land use and transportation system framework across different cities provide the variation, if any, in both the incidence and magnitude of impacts upon further calibration. The addition of clusters that contain transportation-specific impacts (e.g. travel time and costs) provides an extension of the simplified network in the case study. A fertile area for further investigation includes sensitivity analysis with scenarios that depict the choice of route alignment in various site-specific conditions. Comparison of ANP results with other commonly used methods is also a potentially insightful area of investigation. For example, a cost-benefit analysis (B/C) replicated the results of ANP and identified Madison Avenue as the better alternative. However, ANP facilitates the evaluation of land use and transportation interaction qualitatively and quantitatively. Extension of the method of costbenefit in a unified evaluation framework of ANP with risk and opportunity as well as benefit and cost (see Saaty 2003) is a fruitful area for the further evaluation of the LRT alternatives.

From problem definition in a network of interrelated elements, to multi-attribute qualitative and quantitative analysis, high-resolution site-specific spatial assessment, and prediction with limited data deductively and inductively, ANP features are among those that are increasingly recognized as desirable in the recent development of urban systems - of which land use/transportation is the archetype subsystem-from simulation to prediction and evaluation. 
The features are likely to spur further application of ANP in land use/transportation systems forecasting and evaluations in alignment with the development of methods of urban systems. Finally, with the increasingly wide-ranging applications of ANP as the general form of AHP, hybrid methods that are likely to be integrated with ANP (i.e. similarly to the use of the AHP in the development of integrated methods for urban systems analysis) offer a promising venue for future work.

\section{Acknowledgments}

The comments of the anonymous reviewers of JTLU are gratefully acknowledged. The author would also like to thank David Levinson and Kevin Krizek for constructive comments on an earlier version of this paper.

\section{References}

Al-Mosaind, M. A., K. J. Dueker, and J. G. Strathman. 1993. Light-rail transit stations and property values: A hedonic price approach. Transportation Research Record, 1400:90-94.

Alexander, C. 1965. A city is not a tree. Architectural Forum, 122(1;2):58-61; 58-62.

Armstrong, R. J., Jr. 1994. Impacts of commuter rail service as reflected in single-family residential property values. Transportation Research Record, 1466:88-98.

Azis, I. 1990. Analytic hierarchy process in the benefit-cost framework: A post-evaluation of the Trans-Sumatra highway project. European Journal of Operational Research, 48:38-48.

Banai, R. 1993. Fuzziness in Geographical Information Systems: Contributions from the Analytic Hierarchy Process. International Journal of Geographical Information Systems, 7(4):315-329. doi: 10.1080/02693799308901964.

Banai, R. 2006. Public transportation decision-making: A case analysis of the Memphis Light Rail Corridor and route selection with Analytic Hierarchy Process. Journal of Public Transportation, 9(2). URL http://www.nctr.usf.edu/jpt/jptv9n2.htm.

Banai-Kashani, R. 1989. Discrete mode-choice analysis of urban travel demand by the Analytic Hierarchy Process. Transportation, 16(1):81-96. doi: 10.1007/BF00223047.

Batty, M. 1992. Geographical information systems: GIS in urban planning and policy. In GIS in Regional Development Planning, number 51 in UNCRD Meeting report series, pp. 27-60. United Nations Centre for Regional Development, United Nations Centre for Regional Development.

Bennett, R. J. 1985. Quantification and relevance. In R. Johnston, ed., The Future of Geography, pp. 211-224. Methuen.

Bennett, R. J. and J. B. Thornes. 1988. Geography in the United Kingdom 1984-1988: Report to the 26th International Geographical Congress in Sydney, Australia, in August 1988. The Geographical Journal, 154(1):23-48. URL http://www.jstor.org/stable/633474.

Brown, L. A. 1988. Reflections on Third World development: Ground level reality, exogenous forces, and conventional paradigms. Economic Geography, 64(3):255-278. URL http:// www.jstor.org/stable/144073.

Brown, L. A. 1991. Place, Migration and Development in the Third World: An Alternative View. Routledge series on geography and environment. Routledge. 
Calthorpe, P. and W. Fulton. 2001. The regional city: Planning for the end of sprawl. Island Press.

Cantwell, M. D. and R. T. T. Forman. 1993. Landscape graphs: Ecological modeling with graph theory to detect configurations common to diverse landscapes. Landscape Ecology, 8(4):239-255. doi: 10.1007/BF00125131.

Cervero, R. 1994. Rail transit and joint development: Land market impacts in Washington, D.C. and Atlanta. Journal of the American Planning Association, 60(1):83-94. doi: $10.1080 / 01944369408975554$.

Cervero, R. and M. Duncan. 2002a. Land value impacts of rail transit services in Los Angeles County. Report, National Association of Realtors Urban Land Institute.

Cervero, R. and M. Duncan. 2002b. Transit's value-added effects: Light and commuter rail services and commercial land values. Transportation Research Record, 1805(1):8-15. doi: 10.3141/1805-02.

Cervero, R. and J. Landis. 1993. Assessing the impacts of urban rail transit on local real estate markets using quasi-experimental comparisons. Transportation Research Part A, 27(1):13-22. doi: 10.1016/0965-8564(93)90013-B.

Chapin, F. S. and E. Kaiser. 1979. Urban land use planning. Urbana: University of Illinois Press, 3 edition.

Chapin, F. S. and S. Weiss. 1968. A probabilistic model for residential growth. Transportation Research, 2:375-390.

Dantas, A., L. Silveira, and Y. Yamashita. 2001. Integrating GIS and AHP for bus route definition. In Proceedings of the Symposium on Asia GIS. Tokyo.

de la Barra, T. 2001. Integrated land use and transport modeling: The TRANUS experience. In R. K. Brail and R. E. Klosterman, eds., Planning support systems: Integrating geographic information systems, models, and visualization tools. ESRI Press.

Dean, H. and M. Smith. 1993. The impact of the Miami Metrorail on the value of residences near station locations. Land Economics, 69(1):54-66.

Diaz, R. B. 1999. Impacts of rail transit on property values. In Rapid Transit Conference Proceedings. American Public Transportation Association.

Dueker, K. and M. Bianco. 1999. Light-rail-transit impacts in Portland: The first ten years. Transportation Research Record, 1685(1):171-180. doi: 10.3141/1685-22.

Garin, R. A. 1966. A matrix formulation of the Lowry model for intrametropolitan activity allocation. Journal of the American Institute of Planners, 32(6):361-364. doi: 10.1080/01944366608978511.

Hall, P. G. 1996. Cities of Tomorrow: An Intellectual History of Urban Planning and Design in the Twentieth Century. Blackwell, 2 edition.

Harary, F. and J. Rockey. 1976. A city is not a semilattice either. Environment and Planning A, 8(4):375-384. doi: 10.1068/a080375.

Harris, B. and M. Batty. 1993. Locational models, geographic information and planning support systems. Journal of Planning Education and Research, 12(3):184-198. doi: 10.1177/0739456X9301200302.

Huff, D. L. 1963. A probabilistic analysis of shopping center trade areas. Land Economics, 39(1):81-90. URL http://www.jstor.org/stable/3144521.

Jankowski, P. and L. Richard. 1994. Integration of GIS-based suitability analysis and multicriteria evaluating in a spatial decision-support system for route selection. Environment and 
Planning B, 21:323-340.

Jiang, H. and J. R. Eastman. 2000. Application of fuzzy measures in multi-criteria evaluation in GIS. International Journal of Geographical Information Science, 14(2):173-184. doi: $10.1080 / 136588100240903$.

Khasnabis, S. and B. Chaudhury. 1994. Prioritizing transit markets using analytic hierarchy process. Journal of Transportation Engineering, 120(1):74-93.

Landis, J. and M. Zhang. 1998. The second generation of the California urban futures model. part 1: Model logic and theory. Environment and Planning B, 25(5):657-666. doi: $10.1068 / \mathrm{b} 250657$.

Levine, J., S. Park, S. Underwood, and R. Wallace. 1999. Stakeholder preferences in advanced public transportatin system planning. Journal of Public Transportation, 2(2):25-45.

Levy, J. and R. W. Saaty, eds. 2005. Proceedings of the 8th International Symposium on the Analytic Hierarchy Process. International Symposium on the Analytic Hierarchy Process, Creative Decisions Foundation.

Li, X. and A. G.-O. Yeh. 2000. Modelling sustainable urban development by the integration of constrained cellular automata and GIS. International Journal of Geographical Information Science, 14(2):131-152. doi: 10.1080/136588100240886.

Lowry, I. S. 1964. A Model of Metropolis. Rand Corporation.

Malczewski, J. 1999. GIS and Multicriteria Decision Analysis. J. Wiley \& Sons.

Memphis Area Transit Authority. 1997. Memphis regional transit plan. Technical report, ICF Kaiser.

Memphis Area Transit Authority. 2001. Regional rail program: Phase 1 - Corridor selection final report. Report, Parsons Brinkerhoff Quade and Douglas.

Miller, G. A. 1956. The magical number seven, plus or minus two: Some limits on our capacity for processing information. Psychological Review, 63(2):81-97. doi: 10.1037/h0043158.

Mitchell, R. B. and C. Rapkin. 1954. Urban Traffic: A Function of Land Use. Publications of the Institute for Urban Land Use and Housing Studies, Columbia University. Greenwood Press.

Muller, M. R. and J. Middleton. 1994. A Markov model of land-use change dynamics in the Niagara Region, Ontario, Canada. Landscape Ecology, 9(2):151-157. doi: $10.1007 /$ BF00124382.

Nelson, A. 1999. Transit stations and commercial property values: A case study with policy and land-use implications. Journal of Public Transportation, 2(3):77-93.

Niemira, M. P. and T. L. Saaty. 2004. An analytic network process model for financial-crisis forecasting. International Journal of Forecasting, 20(4):573-587. doi: 10.1016/j.ijforecast.2003.09.013.

Nijkamp, P. and H. Voogd. 1983. A survey of multicriteria analysis for development planning. In L. Chatterjee and P. Nijkamp, eds., Urban and Regional Policy Analysis in Developing Countries, pp. 217-229. Boston: Gower.

Piantanakulchai, M. 2005. Analytic network process model for highway corridor planning. In Proceedings of the ISAHP. Honolulu.

Price Waterhouse Coopers. 2001. Review of property value impacts at rapid transit stations and lines.

Rodrigue, J.-P., C. Comtois, and B. Slack. 2006. The Geography of Transport Systems. Routledge. Rogers, A. 1971. Matrix methods in urban and regional analysis. San Francisco: Holden-Day. 
Rogers, M. and M. Bruen. 2000. Using ELECTRE III to choose route for Dublin port motorway. Journal of Transportation Engineering, pp. 313-323.

Saaty, R. W. 1987. The analytic hierarchy process - what it is and how it is used. Mathematical Modelling, 9:161-176.

Saaty, R. W. 2003. Decision Making in Complex Environments: The Analytic Hierarchy Process (AHP) for Decision Making and The Analytic Network Process (ANP) for Decision Making with Dependence and Feedback. Pittsburgh, PA: Creative Decisions Foundation.

Saaty, R. W. 2007. Validating the analytic hierarchy network processes. In Proceedings of ISAHP 2007. Vina del Mar, Chile.

Saaty, T. L. 1980. The Analytic Hierarchy Process. New York: McGraw Hill.

Saaty, T. L. 1986. Axiomatic foundation of the analytic hierarchy process. Magagement Science, 32(7):841-855.

Saaty, T. L. 1990. Physics as a decision theory. European Journal of Operational Research, 48:98-104.

Saaty, T. L. 1994. Highlights and critical points in the theory and application of the analytic hierarchy process. European Journal of Operational Research, 74:426-447.

Saaty, T. L. 1996a. The Analytical Network Process, Decision Making with Dependence And Feedback. Pittsburgh, PA: RWS Publications.

Saaty, T. L. 1996b. Multicriteria Decision Making. Pittsburgh, PA: RWS Publications.

Saaty, T. L. 1998. Reflections and projections on creativity in operations research and management science: A pressing need for a shift in paradigm. INFORMS, 46(1):9-16.

Saaty, T. L. and L. G. Vargas. 1982. The Logic of Priorities. Boston: Kluwer Academic Publishers.

Saaty, T. L. and L. G. Vargas. 2001. Models, Methods, Concepts and Applications of the Analytic Hierarchy Process. Boston: Kluwer Academic Publishers.

Sarkis, J. and R. P. Sundarraj. 2002. Hub location at Digital Equipment Corporation: A comprehensive analysis of qualitative and quantitative factors. European Journal of Operational Research, 137(2):336-347. doi: 10.1016/S0377-2217(01)00138-2.

Shang, J., Y. Tjader, and Y. Ding. 2004. A unified framework for multicriteria evaluation of transportation projects. IEEE Transactions on Engineering Management, 51(3):300-313. doi: 10.1109/TEM.2004.830848.

Simon, H. A. 1981. The sciences of the artificial. Cambridge, Mass.: MIT Press.

Simon, H. A. 1983. Reason in human affairs. Harry Camp lectures at Stanford University, 1982. Stanford, Calif.: Stanford University Press.

Tabucanon, M. and H.-M. Lee. 1995. Multiple criteria evaluation of transportation system improvement projects: The case of Korea. Journal of Transportation Engineering, 29(1).

Tran, L., C. Knight, R. O'Neill, and E. Smith. 2004. Integrated environmental assessment of the mid-Atlantic region with Analytical Network Process. Environmental Monitoring and Assessment, 94(1):263-277.

Transit Cooperative Research Program. 1998. Economic impact analysis of transit investments: Guidebook for practitioners. Report 35, Transportation Research Board.

Transit Cooperative Research Program. 2004. Transit-oriented development in the United States: Experiences, challenges, and prospects. Report 102, Transportation Research Board, Washington, D.C.

Wachs, M. 1985. Management Vs. Political Perspectives on Transit Policymaking. Journal of Planning Education and Research, 4(3):139-147. doi: 10.1177/0739456X8500400302. 
Wegener, M. 1998. GIS and spatial planning. Environment and Planning B, 25:48-52.

Weinberger, R. 2001. Light rail proximity: Benefit or detriment in the case of Santa Clara County, California? Transportation Research Record, 1747(1):104-113. doi: 10.3141/1747-13.

Weinstein, B. and T. L. Clower. 1999. An assessment of the DART LRT on taxable property valuations and transit oriented development. Technical report, University of North Texas, Center for Economic Development and Research. URL http://www.unt.edu/cedr/dart. pdf.

Wu, F. 1998. SimLand: A prototype to simulate land conversion through the integrated GIS and CA with AHP-derived transition rules. International Journal of Geographical Information Science, 12(1):63-82.

Wu, F. and C. J. Webster. 1998. Simulation of land development through the integration of cellular automata and multicriteria evaluation. Environment and Planning B, 25(1):103-126. URL http://www.envplan.com/abstract.cgi?id=b250103.

Yoon, K. and C.-L. Hwang. 1995. Multiple Attribute Decision Making: An Introduction. London: Sage Publications.

Zahedi, F. 1986. The Analytic Hierarchy Process - a survey of the method and its applications. Interfaces, 16(4):96-108.

\section{Appendix Graphs, Markov chains, and the ANP: A brief comparison}

The definition, nomenclature, and methodology of ANP are briefly noted in comparison with the well known methods of Markov chains and graph theory, which have wide-ranging applications to urban systems. The "hamburger" model is a simple example of a network (see Saaty 2003). This model is also shown in Markov chains and graph theory terminology (figure A.1 on the facing page).

The three methods are related in concept. The directional influence of the elements called "clusters" in the ANP can be shown in graph theory by using arrows; Markov chains can be similarly indicated. Additionally, the relative weights (ANP), the probability of transition (Markov chains), or any other property (graph theory) can be numerically indicated. In transportation network analysis (a common area for the application of graph theory), a property like travel time or cost along the paths or links between the nodes in a network is represented numerically by the values of "edges." The graph in figure A.1 is encoded to correspond to the ANP and Markov chains representation of the same system; one indicates that a node is connected to itself or to another node, and zero indicates otherwise. The ANP market share model provides a simple example (see other examples in Saaty 2003). All three methods can be formulated in matrix algebra terms. The ANP "supermatrix" contains the relative weights of the elements derived by column eigenvectors that are multiplied by the weights of the elements in the limit, just as in Markov chain the long-run or equilibrium solution is determined with the matrix of transitional probabilities that are multiplied by the vector of the initial probability of states. The power of the ANP lies in the paired comparison method used to make predictions about the magnitude of the interactions among the elements in a network. The versatile scale that determines priority weights is a proportion $(0-100 \%)$ similar to probability in Markov chains. The interactions between the elements are represented as a network of influences among the criteria, 
which are represented as clusters and nodes within the clusters. A group of nodes with common characteristics are grouped in an ANP cluster, and the interactions can be between all of the clusters, between just clusters and nodes, or both. The ANP can also be explained in terms of Markov chains and graphs. Whereas Markov chains can be defined similarly to a weighted directed graph, in which the weights correspond to the probability of transitions, they can also be defined similarly to ANP through the priority of elements. Weights are non-negative, and the total weight of the outgoing edges is positive.

Figure A.1: ANP, Markov chains, and graphs: A brief comparison.

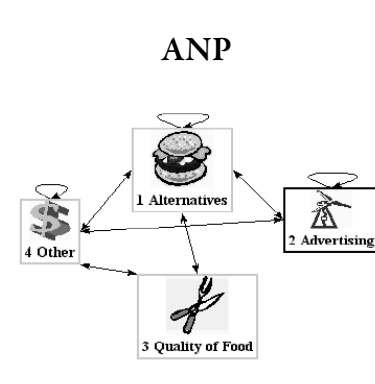

ANP supermatrix

$$
w(k)=\lim _{k \rightarrow \infty} w^{k}, w_{\cdot j}=1
$$

1
2
3
4 $\left[\begin{array}{cccc}0.213 & 0.296 & 0.500 & 0.130 \\ 0.532 & 0.257 & 0 & 0.608 \\ 0.066 & 0.000 & 0 & 0.065 \\ 0.189 & 0.447 & 0.500 & 0.197\end{array}\right]$

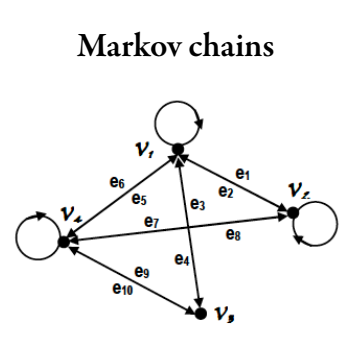

\section{Matrix of transitional probabilities}

$$
P_{i}=1
$$

\begin{tabular}{|c|c|c|c|c|}
\hline & $v_{1}$ & $v_{2}$ & $v_{3}$ & $v_{4}$ \\
\hline$v_{1}$ & $p_{11}$ & $p_{12}$ & $p_{13}$ & $p_{14}$ \\
\hline$v_{2}$ & $p_{21}$ & $p_{22}$ & 0 & $p_{24}$ \\
\hline$v_{3}$ & $p_{31}$ & 0 & 0 & $p_{34}$ \\
\hline$v_{4}$ & $p_{41}$ & $p_{42}$ & $p_{43}$ & $p_{44}$ \\
\hline
\end{tabular}

Graphs

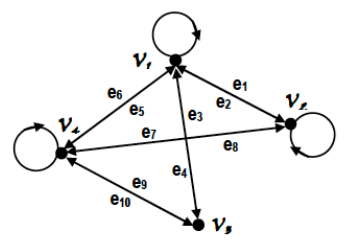

Matrix of graph

$$
G=(V, E)
$$

$v_{1}$
$v_{1}$
$v_{2}$
$v_{3}$
$v_{4}$$\left[\begin{array}{llll}1 & 1 & v_{3} & v_{4} \\ 1 & 1 & 0 & 1 \\ 1 & 0 & 0 & 1 \\ 1 & 1 & 1 & 1\end{array}\right]$

\section{Definitions}

ANP A theory of measurement that uses absolute numbers to determine interactions of elements in a system with feedback expressed in proportions. The system elements are distinguished with inner and outer dependence with relative influence on outcome.

Markov chains A stochastic process that contains a finite number of states like nodes in graph theory. The probability of occurrence of a future state is determined conditionally by the current state. A Markov chain is similar to a weighted directed graph in which the weights correspond to the probability of the transition.

Graphs A graph is a set of nodes (vertices) connected by lines (edges or arcs) to form a network with measurable properties.

\section{Nomenclature}

ANP The criteria and alternatives are represented by clusters and nodes in a network. A group of nodes forms a cluster. A network can include "stakeholders" or participants among the cluster of criteria and the alternatives. 
Markov chains The transitional probabilities of states are graphed in a directional network in a row stochastic matrix.

Graphs Edges, arcs, or links, which provide lines or curves running between a set of points, are called vertices or nodes.

\section{Method of measurement}

ANP Deterministic. The priorities or dominance of network elements as clusters and nodes, which represent multiple criteria and alternatives, are determined through paired comparisons.

Markov chains Probabilistic. The probability of occurrence determines the transition between states.

Graphs Deterministic. Numerical values $(0,1)$ are used to indicate the connection of nodes by edges.

\section{Graphical representation}

Markov chains Transitional probabilities of states are graphed in a directional network corresponding to a row stochastic matrix.

ANP Interactions between clusters are shown in a network of direct and indirect relationships.

Graphs Edges, arcs, or links are shown directionally with lines running between vertices or nodes. A directed graph provides an example of the pattern of transporting material through a network of links.

\section{Matrix formulation}

ANP The rated relationships among the clusters and nodes in an ANP are determined by a limiting supermatrix that is column stochastic.

Markov chains A transition matrix indicates the probability of the next state, which is determined by the probability of the current state.

Graphs Numerical values $(0,1)$ are used in a matrix to indicate the directional connection of nodes by edges. A directional set of such nodes and directed edges with weights is called a network.

Transportation, urban spatial structure, land use, urban growth, and landscape morphology are among the many applications of graph theory and Markov chains (for examples, see Alexander 1965; Cantwell and Forman 1993; Harary and Rockey 1976; Muller and Middleton 1994; Rodrigue et al. 2006). The ANP is increasingly finding use in multicriteria transportation network planning and evaluation (Sarkis and Sundarraj 2002; Shang et al. 2004; Tran et al. 2004). 